\title{
CORRESPONDENCE
}

\section{Science lobbying in Canada needs stepping up}

SIR - Your Editorial 'The other North American election' (Nature 455, 263; 2008) draws attention to an apparent lack of urgency towards general science issues in the Canadian election campaign. This must surely reflect public opinion and therefore inadequate advocacy efforts by the scientific community.

By comparison with the prominence given to sciencerelated issues in the US presidential election, their marginalization in Canadian politics is noticeable (see www. sciencecanada.blogspot.com). During the first 16 days of the election campaign's 37 days, there were only two direct pronouncements on scientific research: one by the Liberal leader on a single visit to a university and the other a mention of research and development by the prime minister during a visit to an industrial firm. That was the scale of attention to science by all main political parties: Conservatives, Liberals, New Democrats and Greens.

Science advocacy in Canada needs to be stepped up. Professional and lobbying organizations that bring science to the attention of policy-makers need to be stronger and more visible. In the United States, for example, there are numerous organizations and professional associations with dynamic and systematic links to policy-makers, Congress and the Senate; in Canada, such relations are largely conducted at a personal level.

The retired politician Preston Manning, cited in your Editorial, is not alone in calling for an independent ministry for science: many scientists have said the same. They are right to insist that science should no longer come under the ministry for industry. Its position there reflects the government's limited grasp of the importance of science policy, not helped by the dearth of scientific and engineering training among parliamentarians.

Unlike Canada, the United

States runs fellowship programmes for training young scientists in science policy and the policy-making process, through its science academies and organizations such as the American Association for the Advancement of Science.

It is time for Canadian scientists to initiate organized efforts to take science into mainstream Canadian society. This will mean strengthening existing professional organizations and establishing new and dynamic networks of science advocates. Only then can we hope that research funding will warrant more than a passing mention in political manifestos.

Mehrdad Hariri Ontario Cancer Institute, University of Toronto, 610 University Avenue, Princess Margaret Hospital, Toronto MSG 2M9, Canada e-mail:mhariri@uhnres.utoronto.ca

\section{Playing the system puts self-citation's impact under review}

SIR - In reply to Tomáš Opatrný's Correspondence 'Playing the system to give low-impact journals more clout' (Nature 455,$167 ; 2008$ ), we would like to point out that the practice of journal self-citation is not new. Thomson Reuters is aware that some journals have used extensive reference to their prior content to influence their citation metrics. The contribution of so-called journal self-citation has been included in Journal Citation Reports since it first appeared in 1975. In recent years, these data have been made more prominent to inform our subscribers of the effects of journal self-citation.

Thomson Reuters also reviews self-citation data for journals in which an exceptionally high self-citation rate artificially influences the impact factor and therefore belies its contribution to the scientific literature. The role of a journal's impact factor as an objective and integral measure becomes questionable at this level of self-citation.

Nine journals received no listing in Journal Citation Reports last year because of exceptionally high self-citation counts; their titles are listed in the Notices file on the journal's website. Journal self-citations will be reviewed each year. Once the problem of excessive self-citation resolves and we can publish an accurate impact factor, the titles will again appear in the journal. Each title continues to be indexed in other Thomson Reuters products.

The cause of the increased 2007 impact factor of Folia Phoniatrica et Logopaedica will be examined as part of the routine review of journal self-citations, and a decision will be made regarding continued listing of the journal in 2008's Journal Citation Reports.

James Testa Thomson Reuters, 3501 Market Street, Philadelphia Pennsylvania 19104, USA e-mail: james.testa @thomsonreuters.com

Austria: investigation likely to have serious consequences

SIR - In the Editorial 'Scandalous behaviour' (Nature 454, 917-918; 2008), you unjustifiably implicate the whole Austrian nation in your comments about a scientific institution. In fact, the dismissal of the rector of the Medical University of Innsbruck had nothing to do with the alleged scientific misconduct in a urology trial that recently took place there.

The rector, Clemens Sorg, was dismissed on the grounds of unsuitability for his post after a thorough investigation by us, the university council, acting as an independent official body.

Moreover, the investigation of the Hannes Strasser misconduct case has been top of the university council's agenda since March 2008. As you point out, the clinical urology trial has been under investigation by AGES, the Austrian agency for health and food safety - an institution comparable to the Food and Drug Administration in the United States. The agency, which issued its final report on the matter in August, routinely checks all investigator-driven clinical trials in Austria. The university council requested immediately that the rector forward the report to the state attorney - the required juridical procedure.

The ongoing investigation is likely to have serious disciplinary and legal consequences. We reject all implications that any official Austrian body is seeking to suppress this investigation.

Guenther Bonn, Christiane Druml, Gabriele Fischer, Christoph Huber, Stephan Laske, Freyja Smolle-Juettner, Richard Soyer University Council of Medical University Innsbruck, Innrain 52,6020 Innsbruck, Austria

\section{As someone wise or funny and probably famous once said ...}

SIR - There comes a time when quotations should be laid to rest. Adam Rutherford, in his Book Review 'The future ain't what it used to be' (Nature 454, 1051; 2008), cites baseball legend 'Yogi' Berra as declaring that it's tough to make predictions, especially about the future.

Maybe he did, but maybe he didn't, or at least maybe he didn't do it first. The same observation has been attributed to numerous other people, including Niels Bohr, Albert Einstein, Mark Twain, Will Rogers, George Bernard Shaw, Winston Churchill, Groucho Marx, Enrico Fermi, Freeman Dyson, Cecil B. DeMille and even Confucius (www.larry.denenberg. com/predictions.html).

Neville W. Goodman Bristol, UK e-mail:nevwgoodman@mac.com 